\title{
The Challenges and Benefits of Multi-generational Undergraduate Research Projects involving Junior Students
}

\author{
Tomislav Terzin, Justin Reinke, Wyatt Warawa, Anna Duitruk, Oleksandra Zubova \\ Department of Science, Augustana Faculty, University of Alberta, Camrose, Alberta, Canada
}

\begin{abstract}
Exposure to research at the undergraduate level can greatly enrich the university experience for the students involved. The benefits of an academic research project to an undergraduate student include: insight and preparation for scientific careers, developing creative and critical thinking skills, encouraging application of coursework concepts to the real-world, and promoting a balance between independent work and collaboration. Despite to all these advantages, undergraduate research is a challenging task for both the student and the supervisor. Undergraduate students have a very limited time available in their schedule to do research and they require more guidance than graduate students. To publish undergraduate research in biology, often more than a single generation of undergraduate researchers is required to be involved in the same project, due to low intensity of research and the interruption of research caused by graduation. The continuation of the same research involving new generation(s) of students brings many challenges described in this paper. Our goal was to provide solutions, using an example of our undergraduate research project on butterfly wing scales. This research was initiated in 2010 and completed in 2015. Work involved four generations of undergraduate students, with the aim of providing equal involvement opportunities to junior and senior biology students alike, as well as welcoming participation from students enrolled in diverse academic disciplines. While the inclusion of such a diverse group of students in an undergraduate research program is attractive, it also presents many novel challenges. We offer recommendations for general principles that could increase the efficiency of the undergraduate research while promoting positive research experience for the students involved.
\end{abstract}

\section{Introduction}

The study of benefits generated by undergraduate research is surprisingly recent and mostly limited to results obtained from US colleges and universities [1], [2], [3]. In this paper we reflect on undergraduate research experience at a small, Canadian, liberal arts campus. Undergraduate research in general has similar goals as liberal arts education, and two can therefore complement each other in the pursuit of developing critical thinking, collaboration and interdisciplinary skills [4]. While most published works study and describe gains from undergraduate research [1], [3], [5], our primary goal in this paper is to discuss challenges. Most studies published in this area are generalized, survey based and performed on a large sample. Our study is case based (see Figure 1) and results were obtained from several students directly involved in the same research program. Through dealing with the challenges, our conclusions are in accordance with all the other studies and are expressed not by numbers, but by students who have names (see Figure 2). Our team of undergraduate students included senior students, junior students and also students from academic disciplines other than biology. Despite technical difficulties, undergraduate research is highly beneficial for students and should be encouraged and supported in all possible ways.

\section{Materials and Methods}

Close-up image of wing scales was created using a Leica S8APO stereomicroscope and digitally converted through the Leica Application Suite V3.7 measurement module.

This study is based on the reflections on challenges of undergraduate research in one particular project (we address it here as the primary research) involving 10 undergraduate researchers over the period of four years. All student authors on this paper were asked to provide written reflections on the various obstacles they faced participating in the primary research. They were also asked to offer possible solutions or improvements. Their reflections were used as a guideline in preparation of this study. Beside this, two 


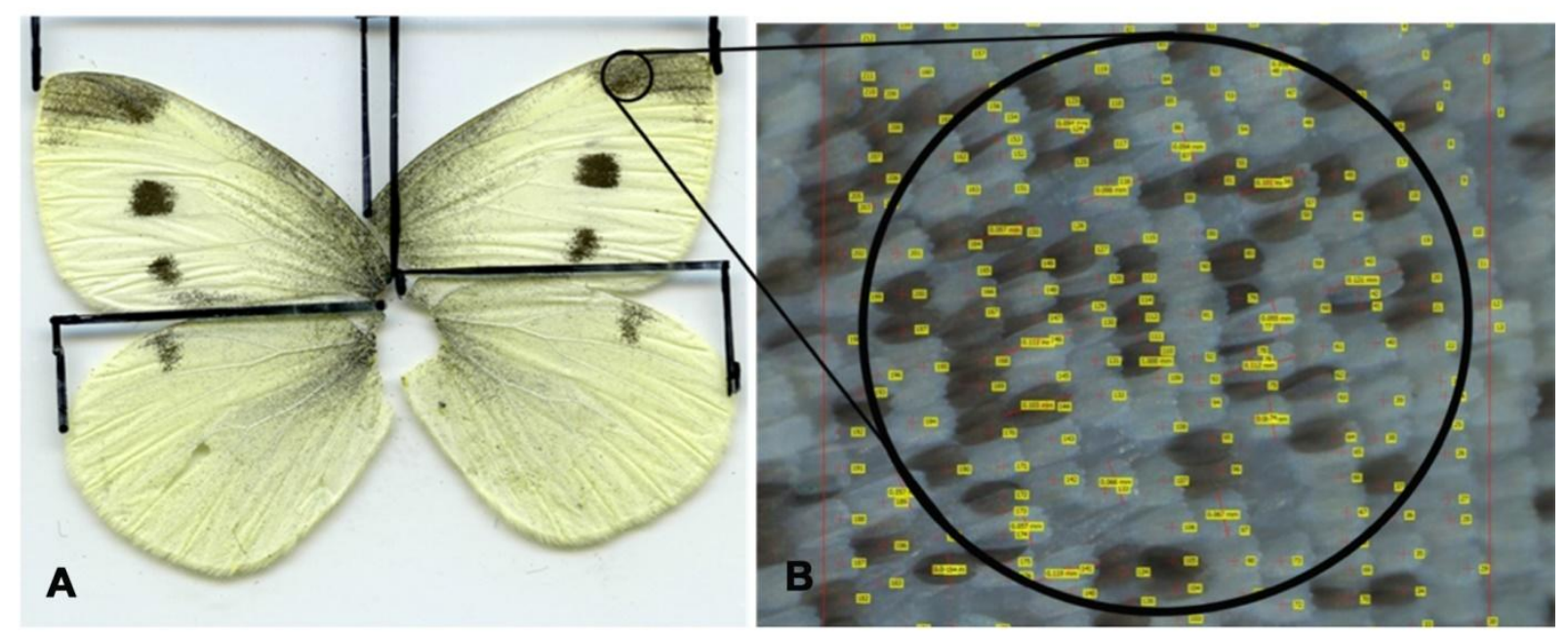

Figure 1. Undergraduate research project that we study in this paper is based on precise measurements of the microscopic epidermal scales (panel b) that create the colour patterns the order lepidoptera is known for. Panel $b$ is a detail of the right front wing of cabbage white butterfly pieris rapae represented in panel a as a microscope slide containing wings only. This project has required multiple generations of students because over a hundred of specimens of various lepidoptera species were analysed in great detail. There is a large number of measurements required for which a digital stereoscope with the appropriate computer software was used. Each generation of students had to learn how to use the equipment which is time consuming for pi. Next challenge of this project was to keep track of specimens and accompanying digital data for each specimen, not mixing the samples while many students were working on various samples. Another challenge was to keep the measuring procedure standardised through four generations of undergraduate research

students (the second and third author on this paper) actively participated in writing this manuscript.

The primary research, which we observed and reflected upon, was performed on dry Lepidoptera specimens of various species. Specimens were sacrificed to make microscope slides of wings suitable for epidermal scale counting (see Figure 1). All involved students were trained how to prepare specimens, how to use stereo microscope, to take images and to use measuring software. About half of the involved students were also participating in data analysis.

\section{Results and Discussion}

In 2010 we initiated an undergraduate research on butterfly wing scales. Although the project started as the SURE (the Summer Undergraduate Research Experience) with a single student who was paid a summer assistant research salary, soon several more students joined as volunteers continuing the project over entire school year. That is how the project operated until its completion. All students were volunteers who worked on the project two hours per week throughout the whole school year (see Figure 2). The fact that there is a large interest among students to join the team (demand is higher than the number of researchers we can accommodate in our research space and schedule) is in the accordance with the results of several large studies about the positive aspects of undergraduate research experience [1], [3], [6], [7]. Although the students who participated in our research expressed positive aspects in their reflections, in this paper we are not going to dwell on it because all positive aspects fall within the categories described in the cited studies. As we stated in the abstract, it is known that the exposure to research at an undergraduate level can greatly enrich the university experience and enhance the preparation for scientific careers. 


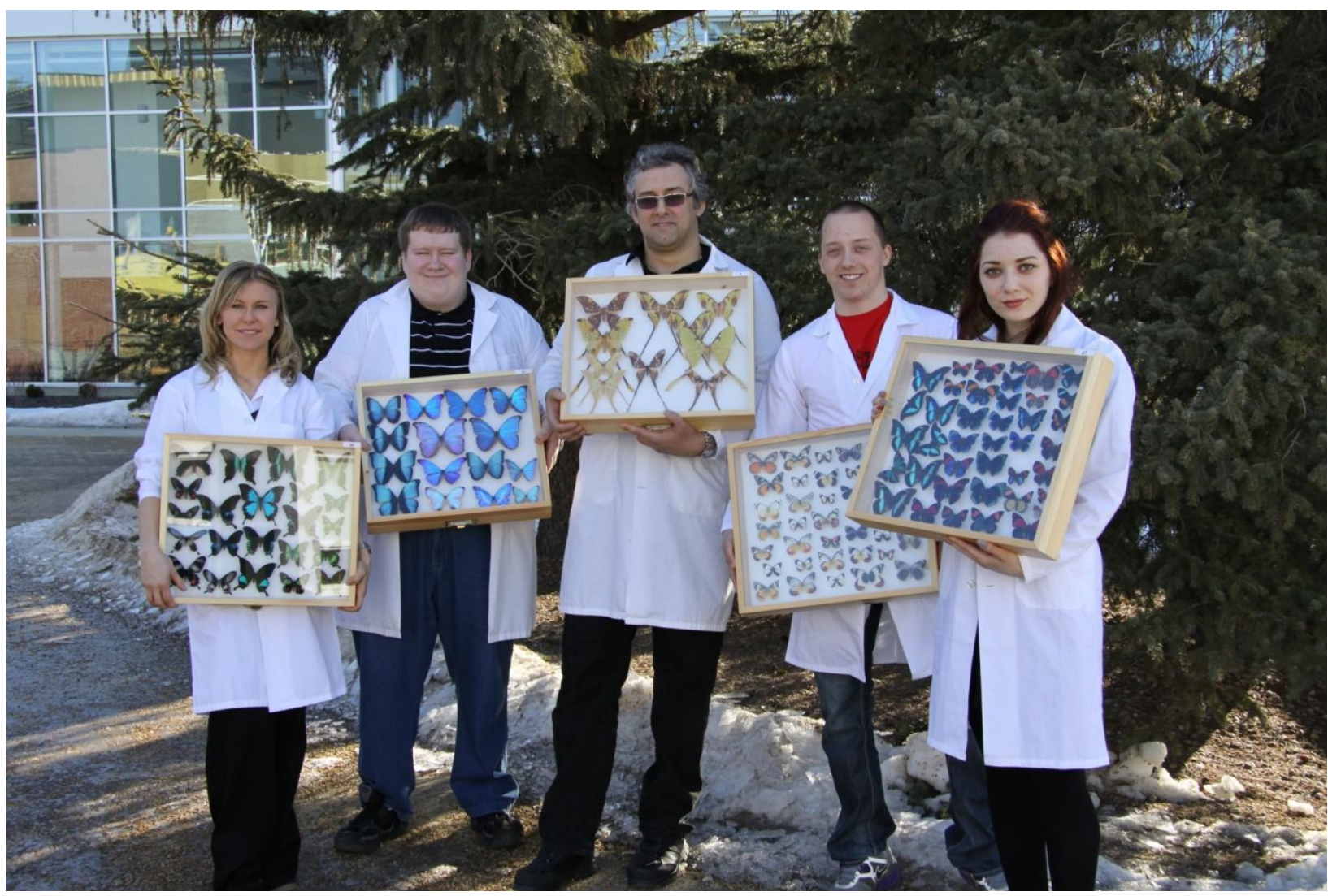

Figure 2. Undergraduate research on butterflies at the Augustana Campus, University of Alberta. Picture was taken in winter 2014. Undergraduate research is ongoing through whole school year. All undergraduate researchers are

volunteers. Four pictured students represent the diversity of our research group. Two of them were fourth year students (graduated in the meantime) and two were first year students. Three students are Biology majors and one is

Business major. In centre is PI. Left to right: Anna Duitruk, Justin Reinke, Tomislav Terzin, Wyatt Warawa and Oleksandra Zubova

The benefits are proven through many large-scale studies, therefore that is not our objective in this paper. Although our research project was specific (butterfly wing scale counting) (see Figure 1), our attempt is to generalise our experience and to make it applicable to many undergraduate research programs in biology through reflections about the challenges. What we did in this paper is research about our research. Survey would not be applicable methodology for this study due to a small sample [2], [3]. We could not quantify efficiency of our research because of the lack of any control group. Therefore, we base our results on the observations and reflections provided by PI and the students involved in the primary research.

\subsection{Why to engage in multi-generational research projects?}

Undergraduate students who pursue academic research often must do so while also balancing the demands of a full load of courses. Many junior students in particular lack effective time management skills and therefore are unable to commit a great deal of time to research projects. In addition, they may have other responsibilities and commitments that they have to balance; these other commitments can make it even more difficult for them to commit to a research project, which slows progress on a research topic. If the goal of undergraduate research is to contribute to the scientific knowledge via peer reviewed publication (which is at 
the same time the most valuable learning experience), completing a project before the researcher graduates is often impractical or impossible. Thus, it is often necessary to have a subsequent generation of students inherit and continue the "in-progress" project in order to bring it to completion. Students are thrilled by the fact that they participate in a real research with the goal to publish. Junior students in particular may be attracted to these projects in order to build professional relationships with their instructors early on in their academic studies, and meet other students with similar goals as themselves. Participating in these research projects gives them a particular focus, which is hard to achieve in course-based undergraduate research [2], [3], [5].

\subsection{Dealing with the restrictions and challenges of continuing a research project}

In contrast to single generation projects, continuing an 'in-progress' project does not provide the flexibility to change the direction of the project as it develops and so the scope of the project is restricted by the previous work completed. It is important that recruited research students are provided with a thorough background of the research topic before undertaking a project (see Table 1). While not an exhaustive list, this can be a combination of: reading related literature to the project, formally shadowing current research students and also discussing the project with the aforementioned students so they can ask questions without fear of judgement from the research supervisor. By doing this, it is hoped to reduce ambiguity and confusion encountered by the incoming research students; a thorough background in the project will help preserve the quality of the data gathered and therefore the research project as a whole. It is further recommended that students are allowed to take on spin-off projects even if it will not further the original research questions and prevent them from continuing the project (see Table 1). This is to avoid a researcher from losing interest in the work, while also preventing the student from being overwhelmed since an apathetic and/or strained researcher will not provide quality work and could jeopardize the integrity of a project. Using this approach will help to refresh a student, and perhaps provide them with a new perspective and motivation that can benefit the original research project when they return to work on the project afterwards.

Consistent data collection is an obvious challenge in multi-generational projects since data may be collected years apart and by separate people. If data collection or preparation procedures are ambiguous in any way, the data is not comparable and much of the work on a project must be redone. In order to ensure consistency it is recommended that a typed step-bystep guide be created for each unique procedure that can be passed on to succeeding generations (see Table 1). These guides should be tested for ambiguity by someone outside the project; this testing should be done because some procedures may seem selfexplanatory to someone who has been working on the project for a long period of time and is familiar with the work, but a new researcher may be completely unfamiliar with the procedure and thus may interpret it incorrectly.

\subsection{Promoting continuity between generations}

When one generation of researchers graduates, they may become unavailable to explain their research to the next generation of researchers on a project. Thus it is important that all aspects of the research are clearly and properly organized by the end of the academic term. However, the pressures and stresses of the exam period leave little time for the sometimes lengthy process of properly summarizing findings and organizing data. This can lead to lost data or lost time by future researchers trying to understand the data, especially if junior students are trying to pick up where the project has been left off. This problem is addressed by recommending that researchers be encouraged to complete their roles on the project far prior to the start of exams and that researchers keep a daily research journal in electronic form that can be passed on with their research (see Table 1). In this journal they would record their thought processes, interpretations of the data, and any difficulties they have encountered so that succeeding students can follow the reasoning of each aspect of the project.

\subsection{Involvement of junior students and students majoring in diverse academic disciplines}

A junior student is bombarded with many new challenges and struggles as they begin their postsecondary educations. Adding the additional responsibilities and stress of a role in an academic research project must be done carefully to ensure that the student is able to make valuable contributions to the project while ensuring their academics do not suffer, and that they gain important experience in 
Table 1. A summary of the challenges encountered in our multigenerational undergraduate research project on Lepidoptera and our proposed solutions to the encountered challenges. The research took place over the course of 4 years starting in 2010. The team comprised of senior and junior students attending Augustana Campus, Univeristy of Alberta in Camrose, Alberta, Canada

\begin{tabular}{|l|c|}
\hline Challenges & Solutions \\
\hline $\begin{array}{l}\text { Continuing a research project with successive } \\
\text { generations of students }\end{array}$ & $\begin{array}{l}\text { Provide a thorough background to the project } \\
\text { before starting }\end{array}$ \\
& $\begin{array}{l}\text { Develop step-by-step guides for each procedure } \\
\text { Encourage spin off projects }\end{array}$ \\
\hline Promoting continuity between generations & $\begin{array}{l}\text { Encourage graduating students to complete } \\
\text { duties much before final exams }\end{array}$ \\
& $\begin{array}{l}\text { All students should write in a daily research } \\
\text { journal which is passed on with their data }\end{array}$ \\
\hline Involving junior students & $\begin{array}{l}\text { Pair up a senior student with a junior student } \\
\text { Ease them into the project with simple tasks } \\
\end{array}$ \\
& $\begin{array}{l}\text { such as reading literature and informally } \\
\text { shadowing another student }\end{array}$ \\
& Ensure they can handle the responsibility \\
\hline
\end{tabular}

research and the area of study. This may require easing a junior researcher into a project by having them shadow a senior researcher informally or simply read related journal articles until they have settled in to life as a university student (see Table 1). Not surprisingly, it has been found that the intellectual maturity of a student and their overall grade point average can greatly influence the ability to achieve project goals [9]. Therefore it is important to take extra care when considering an addition of a junior student to a research team. While junior students may be written off for lacking some of the theoretical background, they can often bring a level of passion and curiosity that is unmatched by senior students which can energize a research team. Involving junior students is also one of the best ways for addressing the challenge of continuation in multi-generational projects. A junior student paired up with a senior student becomes invaluable for the next year when that senior student has graduated (see Figure 2; Table 1). Therefore it is advised that junior students be seriously considered when recruiting student research assistants and they express interest, while using caution as mentioned previously. In the same way as junior students, students who join research outside of their field of specialization are often thrilled to try something new. Also in many ways they are in the same position as junior students who major in the research subject area. In a few words, they are new to it. It is recommended to accept only senior students from diverse academic disciplines to join research, and only if students express interest and initiative to join research. This can usually happen when they hear about it from their classmates, roommates and friends. Due to their similarity to junior students in many respects, it is recommended to also ease them into the project and ensure they are equipped to handle the task, as mentioned before (see Table 1). Based on our experience, active recruitment of researchers outside of the discipline is not recommended. However, when "out of field" senior student joins the team, they can often bring new and valuable perspective to the research; this refreshed and unique perspective enriches it in various, sometimes unpredictable and creative ways. Adding students from other academic disciplines can also improve project outcomes, the scope of the project and the creativity of potential solutions studied in the projects. This is true as long as the students are academically successful [9].

\section{Conclusions}

Despite to all advantages, undergraduate research can be a challenging task for all involved. It is particularly so if a goal is to generate publishable data. Multigenerational research projects provide sufficient time to accomplish this goal. However, it is crucial that consistent data collection and the continuity between generations (coupling junior and senior undergraduate researchers involved on the same project) are achieved. Detailed journals, protocols and 
procedures written by students for students using practical language are essential tools in achieving the continuity and efficacy of multigenerational undergraduate research projects. In addition, diversifying the research team with junior students and students from other academic disciplines can add a level of quality, passion and creativity that can be hard to achieve otherwise. While extra care must be taken when undertaking a multi-generation undergraduate research project (especially if junior students are to be involved), the benefits experienced by both the students and the research supervisor(s) makes this approach a viable one to consider if the goal of the research is to publish. The multi-generation approach allows several generations of undergraduate researchers to contribute their efforts toward a single publishable research while each gaining valuable experience in research and in the area of study.

\section{Acknowledgement}

We would like to thank Dr. Jonathan Mohr, former Chair of the Science Department, Augustana Campus, University of Alberta, for providing the funds for the purchase of stereomicroscope and the measuring software used in our research. We thank all Augustana undergraduate students who participated in the research project which yielded the experience on which we base this study. Those students, listed chronologically (most of them already graduated) are: M.Sc. Afrin Biswas, Andrew Kostyniuk, James Vy, Brooke Smith, Scott Myshyniuk, and Sheldon Browse. We thank student Tonya Simpson for taking picture used in Figure 2. This research was supported by the multiple Augustana Research Grants awarded to Dr. Tomislav Terzin.

\section{References}

[1] Adedokun O. A., Parker L. C., Childress A., Burgess W., Adams R., Agnew C. R, Leary J., Knapp D., Shields C., Lelievre S. and Teegarden D. (2014) 'Effects of Time on Perceived Gains from an Undergraduate Research Program', CBE-Life Sciences Education 13, pp. 139-148.

[2] Junge B, Quinones C, Kakietek J, Teodorescu D and Marsteller P. (2010) 'Promoting Undergraduate Interest, Preparedness, and Professional Pursuit in the Sciences: an Outcomes Evaluation of the SURE Program at Emory University', CBE-Life Sciences Education 9, pp. 119-132.
[3] Lopatto D. (2004) 'Survey of Undergraduate Research Experiences (SURE): First Findings', CBE-Life Sciences Education 3, pp. 270-277.

[4] Kaiser BN, Mishler DM, Peoples WA, and Wells AS. (2014) 'Undergraduate Research and a Liberal Arts Education: Similar Goals, Similar Solutions', Journal of College Science Teaching 43(5), pp. 48-54.

[5] Hunter P. (2007) 'Undergraduate research - Winning the Battle for Students' hearts and minds', EMBO reports 8(8), pp. 717-19.

[6] Lopatto D. (2007) 'Undergraduate Research Experiences Support Science Career Decisions and Active Learning', CBE-Life Sciences Education 6, pp. 297-306.

[7] Russel SH, Hancock MP and McCullough J. (2007) 'Benefits of Undergraduate Research Experience', Science 316, pp. 548-549.

[8] Bangera G and Brownell S. (2014) 'Course-Based Undergraduate Research Experiences can make Scientific Research more Inclusive', CBE-Life Sciences Education 13, pp. 602-606.

[9] Aktas CB. (2015) 'Reflections on interdisciplinary sustainability research with undergraduate students', International Journal of Sustainability in Higher Education 16(3), pp. 354-366. 